Research Article

\title{
Seismic Isolation Performance Evaluation for a Class of Inerter-Based Low-Complexity Isolators
}

\author{
Fei Cao, ${ }^{1}$ Michael Z. Q. Chen $\mathbb{D}^{1},{ }^{1}$ and Yinlong $\mathrm{Hu}^{2}$ \\ ${ }^{1}$ School of Automation, Nanjing University of Science and Technology, Nanjing 210094, China \\ ${ }^{2}$ College of Energy and Electrical Engineering, Hohai University, Nanjing 211100, China \\ Correspondence should be addressed to Michael Z. Q. Chen; mzqchen@outlook.com
}

Received 10 July 2020; Revised 17 September 2020; Accepted 28 September 2020; Published 22 October 2020

Academic Editor: Marta Berardengo

Copyright $(2020$ Fei Cao et al. This is an open access article distributed under the Creative Commons Attribution License, which permits unrestricted use, distribution, and reproduction in any medium, provided the original work is properly cited.

In this paper, the seismic base isolation problem for all low-complexity networks containing one inerter, one spring, and one damper is studied based on a multi-degree-of-freedom model. The analytical solutions for the $\mathrm{H}_{2}$ performance optimization are derived, and the traditional tuned mass damper (TMD) is employed for comparison. Extensive numerical simulations are performed to verify the effectiveness of the obtained results. The results show that for different seismic wave excitations, some isolators are better than TMD in controlling the displacement of the main structure. Moreover, with the increase of the TMD mass ratio, the isolation performances of the inerter-based isolators are increasingly better than that of TMD.

\section{Introduction}

With the rapid development of the economy and the continuous progress of urbanization, the safety of buildings is particularly important. According to statistics, more than 5 million earthquakes occur on earth every year, most of which are ignored because of their small magnitudes, but a strong earthquake will cause great damage to buildings.

Structural vibration control is an effective way to reduce a structure's dynamic response under the excitation of earthquake and wind, which can be classified as two basic forms: base isolation and dynamic vibration absorption (DVA). The base isolation is to install a vibration isolator between the source and the controlled object [1], while the dynamic vibration absorption is to attach an auxiliary system to the controlled object, and such a device is also known as tuned mass damper (TMD) $[2,3]$.

The traditional passive structural vibration control mainly utilizes three classical mechanical components, i.e., mass, spring, and damper. A mass has only one endpoint that can move freely, namely, the center of mass, and the other endpoint is the inertial reference frame (usually the ground). Therefore, mass is not a real two-endpoint component. At the beginning of this century, Smith first proposed the concept of the inerter [4]. Inerter is defined as a device where the applied force at its two endpoints is proportional to the relative acceleration between the two endpoints [5]. The symbol of inerter is shown in Figure 1. The dynamic equation of inerter is $F=b\left(\dot{v}_{2}-\dot{v}_{1}\right)$, where the proportional factor $b$ is called the inertance. The physical realization of inerter includes the rack pinion inerter $[4,6]$, the ball screw inerter [7], and the hydraulic inerter [8-10]. The unique feature of inerter is that large inertance can be achieved through a small physical mass. Inerter was first applied in the suspension system of Formula One racing cars [6] and was called "J-damper" at that time. Afterwards, inerter has been broadly studied in the mechanical engineering field, such as vehicles [11-17], wind turbines [18-20], civil engineering structures [21-25], and other vibration control systems [26-30]. Recently, inerter has also been applied to wave energy converters [31,32].

In structural vibration control, the base isolation device and the dynamic vibration absorption device see new advances after introducing inerter. In terms of base isolation, Wang et al. proposed two basic inerter-based configurations and verified that appropriate inerter-based configurations can effectively reduce structural vibration under earthquake action [33]. Hu et al. proposed the inerter-based isolator, 


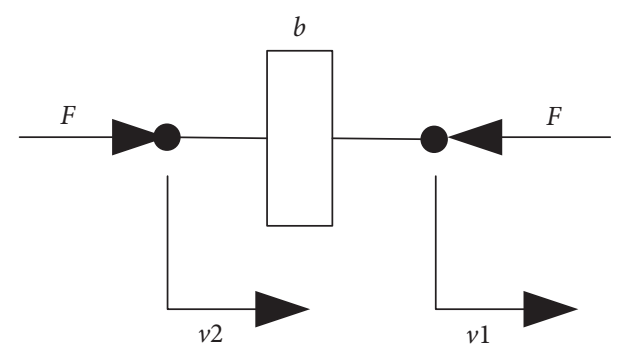

Figure 1: Symbolic representation of inerter [4].

where the displacement transmissibility problem and the force transmissibility problem were considered, and the damping effect of the proposed inerter-based isolator in terms of the performance of $\mathrm{H}_{2}$ measurement and the performance of $H_{\infty}$ measurement was studied based on a single-degree-of-freedom system [34, 35]. In terms of dynamic vibration absorption, $\mathrm{Hu}$ et al. proposed an inerterbased dynamic vibration absorber (IDVA), where parameter optimization was conducted in the case of single degree of freedom, and made a comparison with the traditional dynamic vibration absorber [36]. In order to provide further explanation to the mass amplification characteristics of inerter, Marian et al. first proposed a tuning mass damper inerter (TMDI) combining the traditional tuning mass damper and inerter, and studied the optimal parameters [37]. Other inerter-based structural control configurations installed at the base or interstorey of a building have also been proposed, such as tuned viscous mass damper (TVMD) [38] and tuned inerter damper (TID) [39, 40].

Note that for the existing results on inerter-based structural vibration control, a (or some) specific inerterbased network is commonly employed. For example, the inerter-based isolator in [34, 35] is concerned with five networks containing at most one inerter, one spring, and one damper. The inerter-based DVA (IDVA) in [36] was illustrated based on six networks containing at most one inerter, one spring, and one damper. The TVMD in [38] is essentially a parallel connection of an inerter and a damper, and then in series with a spring. The TID in $[39,40]$ is a parallel connection of a spring and a damper, and then in series with an inerter. Since numerous networks can be constructed by using inerters, dampers, and springs, then comprehensive study for an entire subclass of inerter-based networks (such as all the networks containing one inerter, one damper, and one spring in this paper) is essential, such that general conclusions including the performance limitations, amongst others, can be obtained. This motivates the investigation presented in this paper.

In this paper, all the networks containing one spring, one damper, and one inerter proposed in [35] are considered for the seismic vibration problem. The main difference from $[34,35]$ is that in $[34,35]$, the displacement transmissibility problem and force transmissibility problem were considered; while in this paper, the impact of seismic acceleration on the displacement of buildings is studied, which is the main consideration in seismic research. Moreover, a multidegree-of-freedom model is employed in this paper which is more practical than the single-degree-of-freedom model in $[34,35]$.

The organization of this paper is as follows. In Section 2, the optimal solutions for the $\mathrm{H}_{2}$ performance of the lowcomplexity networks with one inerter, one spring, and one damper, and the TMD are derived, based on a multi-degreeof-freedom model. In Section 3, a numerical example is used for performance comparison and analysis, and eleven seismic waves are used for verification. In Section 4 , a brief conclusion is drawn.

\section{Analytic Solution of $\mathbf{H}_{2}$ Performance Optimization}

2.1. Method of $\mathrm{H}_{2}$ Optimization of Inerter-Based Isolator. The schematic diagram of the low-complexity networks with only one inerter, one spring, and one damper (hereinafter referred to as inerter-based isolators) is shown in Figure 2.

In Section 2.1, structure C3 is taken as an example to illustrate the method of $\mathrm{H}_{2}$ optimization of the inerter-based isolator, and the schematic diagram of structure C3 installed in the multi-degree-of-freedom model is shown in Figure 3. The damping of certain structures is generally small in practice and would have little influence on the analysis of these structures. In order to obtain the analytic solution, the influence of damping of the main structure is ignored.

For regular uniform multistorey buildings, the low-order mode usually plays a major role under seismic excitation [40]. Therefore, this paper will conduct $\mathrm{H}_{2}$ performance optimization for the first-order mode of a multistorey building and conduct a comparative analysis with the $\mathrm{H}_{2}$ performance of TMD installed at the top floor of the building.

Its motion equation is

$$
\left\{\begin{array}{l}
M \ddot{X}+K X+F \Gamma_{0}=-M E \ddot{x}_{g} \\
F=b \ddot{x}_{b}=k\left(x_{1}-x_{c}\right)=c\left(\dot{x}_{c}-\dot{x}_{b}\right),
\end{array}\right.
$$

where $M$ and $K$ are, respectively, the mass matrix and stiffness matrix of the main structure; $b, c$, and $k$ are the inertance, damping coefficient, and stiffness, respectively; $\ddot{X}$ and $X$ are the acceleration matrix and displacement matrix of the main structure, respectively, where $X=\left[x_{1}, x_{2}, \ldots, x_{n}\right]^{T} ; \ddot{x}_{b}, \dot{x}_{b}$, and $x_{b}$ are the acceleration, velocity, and displacement of the inerter, respectively; $\ddot{x}_{g}$ is the earthquake acceleration; respectively, $\dot{x}_{c}$ and $x_{c}$ represent the velocity and displacement of the damper; $\Gamma_{0}=[1,0, \ldots, 0]^{T}$ is the indicator vector for installation; $E=$ $[1,1, \ldots, 1]^{T}$ is the unit volume; the mass matrix of the main structure $M=\operatorname{diag}\left(\left[m_{1}, m_{2}, \ldots, m_{n}\right]\right) ;$ and the stiffness matrix of the main structure $K=\left[\begin{array}{cccc}k_{1}+k_{2} & -k_{2} & \ldots & \\ -k_{2} & k_{2}+k_{3} & & \\ \vdots & & & -k_{n} \\ & & -k_{n} & k_{n}\end{array}\right]$; the above responses are the responses to the ground.

Let $X=\phi_{1} q$, where $\phi_{1}$ is the first mode and $q$ is the generalized displacement, by substituting it into equation (1) and carrying out the Laplace transform of equation (1), 


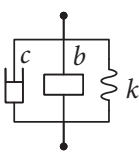

(a)

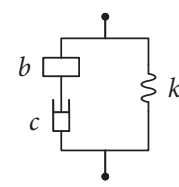

(b)

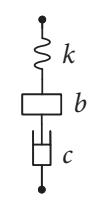

(c)

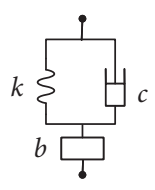

(d)

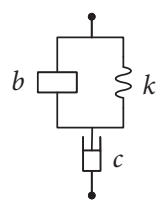

(e)

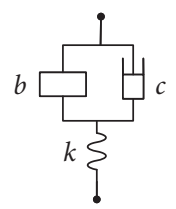

(f)

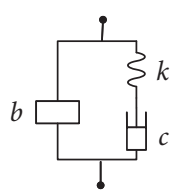

(g)

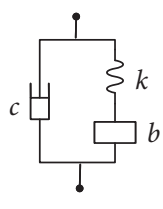

(h)

FIgURE 2: The low-complexity networks with only one inerter, one spring, and one damper [35]. C4 is TID [39, 40], and C6 is TVMD [38]. (a) C1. (b) C2. (c) C3. (d) C4. (e) C5. (f) C6. (g) C7. (h) C8.

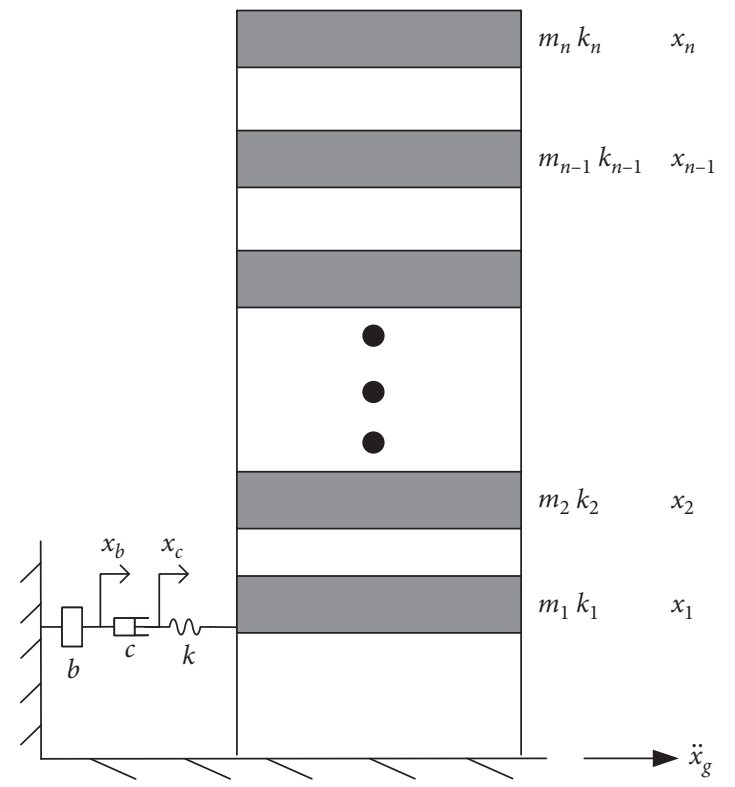

FIGURE 3: Schematic diagram of structure C3 installed in the multi-degree-of-freedom model.

the transfer function of seismic acceleration to the generalized displacement of the main structure can be obtained:

$$
H(s)=\frac{q}{\ddot{x}_{g}}=\frac{-\alpha\left(2 \delta \zeta w_{1} s^{2}+\delta\left(w_{1}^{2} / \lambda\right) s+2 \zeta\left(w_{1}^{3} / \lambda\right)\right)}{\left(s^{2}+w_{1}^{2}\right)\left(2 \delta \zeta w_{1} s^{2}+\delta\left(w_{1}^{2} / \lambda\right) s+2 \zeta\left(w_{1}^{3} / \lambda\right)\right)+2 \gamma \delta \zeta\left(w_{1}^{3} / \lambda\right) s^{2}},
$$

where $w_{1}=\sqrt{K_{1} / M_{1}}$ is the first mode frequency, $M_{1}$ is the mass of the first mode, $K_{1}$ is the stiffness of the first mode, and $\delta=\left(b / M_{1}\right)$ is inertance-to-mass ratio; damping ratio is $\zeta=\left(c / c_{r}\right)$, where $c_{r}=2 w_{1} M_{1}=2 \sqrt{M_{1} K_{1}}$ is the critical damping coefficient of the system without structure C3; stiffness ratio is $\lambda=\left(K_{1} / k\right) ; \quad \alpha=\left(\phi_{1}^{T} M E / M_{1}\right)$; $\gamma=\phi_{1}^{T} \Gamma_{0} \phi_{1(1)}$, where $\phi_{1(1)}$ is the first mode coordinates of the bottom layer.

Since seismic excitation contains multiple frequency bands and is a random disturbance, it is more appropriate to use $\mathrm{H}_{2}$ norm to evaluate the seismic damping effect of the adopted structure on the main structure. The goal of $\mathrm{H}_{2}$ performance optimization is to minimize the total vibration energy of the main structure when it is disturbed by white noise. Using the method in Reference [41], the $\mathrm{H}_{2}$ performance index $I$ of the system can be expressed as

$$
I=\|\widehat{H}(s)\|_{2}^{2} \text {. }
$$

For a linear time-invariant closed-loop system,

$$
\begin{aligned}
& \dot{x}=A_{c l} x+B_{c l} w, \\
& z=C_{c l} x+D_{c l} w,
\end{aligned}
$$

where $w$ is the external input and $z$ is the control output. The $\mathrm{H}_{2}$ norm from the input $w$ to the output $z$ of the system can be directly calculated with the following theorem. 
Theorem 1 (see [41]). Considering closed-loop system (4), if $A_{c l}$ is unstable or $D_{c l} \neq 0$, then the $\mathrm{H}_{2}$ norm from the input $w$ to the output $z$ of the system is infinite; otherwise,

$$
\|H\|_{2}^{2}=\operatorname{trace}\left(C_{c l} \mathrm{P} C_{c l}^{T}\right)=\operatorname{trace}\left(B_{c l}^{T} \mathrm{~S} B_{c l}\right),
$$

where $P$ and $S$ are the solutions of the following Lyapunov equation:

$$
\begin{aligned}
& A_{c l} P+P A_{c l}^{T}+B_{c l} B_{c l}^{T}=0, \\
& A_{c l}^{T} S+S A_{c l}+C_{c l}^{T} C_{c l}=0 .
\end{aligned}
$$

According to Theorem 1, for a given stable transfer function $T(s)$,

$$
T(s)=\frac{b_{n-1} s^{n-1}+\cdots+b_{1} s+b_{0}}{s^{n}+a_{n-1} s^{n-1}+\cdots+a_{1} s+a_{0}} .
$$

Its $\mathrm{H}_{2}$ norm can be calculated as follows:

$$
\|T(s)\|_{2}^{2}=\left\|C(s I-A)^{-1} B\right\|_{2}^{2}=C L C^{T},
$$

where matrices $A, B$, and $C$ are the minimum phase realization of $T(s)$, and matrix $L$ is the solution of the following Lyapunov equation:

$$
A L+L A^{T}+B B^{T}=0 .
$$

Therefore, $\mathrm{H}_{2}$ performance index $I$ of the system can be calculated analytically using the above method, and the specific steps are summarized as follows.

The method of $\mathrm{H}_{2}$ optimization of the inerter-based isolator is as follows:

(i) Step 1. The transfer function $H(s)$ of the inerterbased isolator is listed, and the analytic expression of the $\mathrm{H}_{2}$ performance index $I$ of the system is obtained by using the method of solving the $\mathrm{H}_{2}$ performance index for the given inertance-to-mass ratio $\delta$.

(ii) Step 2. The analytic expression of the $\mathrm{H}_{2}$ performance index $I$ is obtained, and the derivatives of stiffness ratio $\lambda$ and damping ratio $\zeta$ are obtained, respectively, and set each as 0 to obtain the simplified optimal stiffness ratio $\lambda_{\text {opt }}$ and the optimal damping ratio $\zeta_{\text {opt }}$.

(iii) Step 3. The obtained optimal stiffness ratio $\lambda_{\text {opt }}$ and damping ratio $\zeta_{\text {opt }}$ are substituted into the analytic expression of the system $\mathrm{H}_{2}$ performance index $I$ to obtain the optimal $\mathrm{H}_{2}$ performance $I_{\mathrm{opt}}$.

2.2. Analytic Solution of $\mathrm{H}_{2}$ Performance Optimization for Inerter-Based Isolator. On the premise of the given inertance-to-mass ratio $\delta$, the analytic solutions of $\mathrm{H}_{2}$ performance optimization, optimal stiffness ratio $\lambda_{\text {opt }}$, and optimal damping ratio $\zeta_{\text {opt }}$ of all the inerter-based isolator $\mathrm{C} 1-\mathrm{C} 8$ installed in the multi-degree-of-freedom model are given.
2.2.1. Structure C1. The analytic expression of the $\mathrm{H}_{2}$ performance index of structure $\mathrm{C} 1$ is

$$
I_{C 1}=\frac{\lambda \alpha^{2}}{4(\lambda+\gamma) \zeta \gamma w_{1}^{3}} .
$$

For a given inertance-to-mass ratio $\delta$, the optimal damping ratio $\zeta_{\text {opt }}$ is $\infty$, and the optimal $\mathrm{H}_{2}$ performance index $I_{C 1 \text {,opt }}$ is 0 , or the optimal stiffness ratio $\lambda_{\text {opt }}$ is 0 , and the optimal $\mathrm{H}_{2}$ performance index $I_{\mathrm{Cl} \text {,opt }}$ is 0 .

2.2.2. Structure C2. The analytic expression of the $\mathrm{H}_{2}$ performance index of structure $\mathrm{C} 2$ is

$$
I_{C 2}=\frac{\lambda \alpha^{2}\left(4 \lambda \gamma \delta \zeta^{2}+4 \lambda \zeta^{2}+\lambda \delta^{2}+\gamma \delta^{2}\right)}{4 \gamma \zeta w_{1}^{3}(\lambda+\gamma)^{2} \delta^{2}} .
$$

For a given inertance-to-mass ratio $\delta$, the optimal stiffness ratio $\lambda_{\text {opt }}$ is 0 , and the optimal $\mathrm{H}_{2}$ performance index $I_{C 2, \mathrm{opt}}$ is 0 .

2.2.3. Structure C3. The analytic expression of the $\mathrm{H}_{2}$ performance index of structure C3 is

$$
I_{C 3}=\frac{\alpha^{2}\left(4 \lambda^{2} \delta^{2} \zeta^{2}-8 \lambda \delta \zeta^{2}+4 \gamma \delta \zeta^{2}+\delta^{2}+4 \zeta^{2}\right)}{4 \gamma \zeta w_{1}^{3} \delta^{2}} .
$$

For a given inertance-to-mass ratio $\delta$, the optimal stiffness ratio $\lambda_{\text {opt }}$ is

$$
\lambda_{\mathrm{opt}}=\frac{1}{\delta}
$$

For a given inertance-to-mass ratio $\delta$, the optimal damping ratio $\zeta_{\text {opt }}$ is

$$
\zeta_{\mathrm{opt}}=\frac{\sqrt{4}}{4} \sqrt{\frac{\delta}{\gamma}}
$$

The optimal $\mathrm{H}_{2}$ performance index $I_{C 3 \text {,opt }}$ is

$$
I_{C 3, \mathrm{opt}}=\frac{\alpha^{2}}{\gamma w_{1}^{3} \sqrt{\delta / \gamma}}
$$

2.2.4. Structure C4 (TID). The analytic expression of the $\mathrm{H}_{2}$ performance index of structure $\mathrm{C} 4$ is

$$
I_{C 4}=\frac{\alpha^{2}\left(4 \lambda^{2} \gamma \delta \zeta^{2}+\delta^{2} \lambda^{2}+4 \lambda^{2} \zeta^{2}-\lambda \gamma \delta^{2}-2 \delta \lambda+\gamma^{2} \delta^{2}+2 \gamma \delta+1\right)}{4 \lambda^{2} \gamma \zeta w_{1}^{3} \delta^{2}} .
$$

For a given inertance-to-mass ratio $\delta$, the optimal stiffness ratio $\lambda_{\text {opt }}$ is

$$
\lambda_{\mathrm{opt}}=\frac{2\left(\gamma^{2} \delta^{2}+2 \gamma \delta+1\right)}{\delta(\gamma \delta+2)}
$$


For a given inertance-to-mass ratio $\delta$, the optimal damping ratio $\zeta_{\text {opt }}$ is

$$
\zeta_{\mathrm{opt}}=\frac{\delta \sqrt{\left(3 \gamma^{2} \delta^{2}+4 \gamma \delta\right) /(16+16 \gamma \delta)}}{1+\gamma \delta}
$$

The optimal $\mathrm{H}_{2}$ performance index $I_{C 4, \mathrm{opt}}$ is

$$
I_{C 4, \mathrm{opt}}=\frac{\alpha^{2}(3 \gamma \delta+4)}{8(1+\gamma \delta) w_{1}^{3} \sqrt{\left(3 \gamma^{2} \delta^{2}+4 \gamma \delta\right) /(16+16 \gamma \delta)}}
$$

2.2.5. Structure C5. The analytic expression of the $\mathrm{H}_{2}$ performance index of structure C5 is

$$
I_{C 5}=\frac{\alpha^{2}\left(4 \lambda^{2} \gamma \delta \zeta^{2}+\delta^{2} \lambda^{2}+4 \lambda^{2} \zeta^{2}-2 \delta \lambda+1\right)}{4 \gamma \zeta w_{1}^{3}\left(\lambda^{2} \delta^{2}-2 \delta \lambda+1\right)} .
$$

For a given inertance-to-mass ratio $\delta$, the optimal stiffness ratio $\lambda_{\text {opt }}$ is

$$
\lambda_{\text {opt }}=0
$$

For a given inertance-to-mass ratio $\delta$, the optimal damping ratio $\zeta_{\text {opt }}$ is $\infty$, and the optimal $\mathrm{H}_{2}$ performance index $I_{C 5 \text {,opt }}$ is 0 .

2.2.6. Structure C6 (TVMD). The analytic expression of the $\mathrm{H}_{2}$ performance index of structure $\mathrm{C} 6$ is

$$
I_{C 6}=\frac{\alpha^{2}\left(\delta^{2} \lambda^{2}+4 \lambda^{2} \zeta^{2}+\lambda \gamma \delta^{2}-2 \delta \lambda+1\right)}{4 \gamma \zeta w_{1}^{3}} .
$$

For a given inertance-to-mass ratio $\delta, \lambda$ has no optimal value when $\delta=[(2(3-2 \sqrt{2})) /(3 \gamma),(2(3+2 \sqrt{2})) /(3 \gamma)]$; when $\delta$ is equal to anything else, the optimal stiffness ratio $\lambda_{\text {opt }}$ is

$$
\lambda_{\mathrm{opt}}=\frac{2-\gamma \delta}{2 \delta\left((3 / 8) \gamma^{2} \delta^{2}-(3 / 2) \gamma \delta+(3 / 2)-(1 / 8) \sqrt{9 \gamma^{4} \delta^{4}-72 \gamma^{3} \delta^{3}+184 \gamma^{2} \delta^{2}-160 \gamma \delta+16}\right)}
$$

For a given inertance-to-mass ratio $\delta, \zeta$ has no optimal when $\delta$ is equal to anything else, the optimal damping ratio value when $\delta=[(2(3-2 \sqrt{2})) /(3 \gamma),(2(3+2 \sqrt{2})) /(3 \gamma)] ; \quad \zeta_{\mathrm{opt}}$ is

$$
\zeta_{\mathrm{opt}}=\frac{1}{8} \delta \sqrt{8+6 \gamma^{2} \delta^{2}-24 \gamma \delta-2 \sqrt{9 \gamma^{4} \delta^{4}-72 \gamma^{3} \delta^{3}+184 \gamma^{2} \delta^{2}-160 \gamma \delta+16}}
$$

When the optimal stiffness ratio $\lambda_{\text {opt }}$ and damping ratio $\zeta_{\text {opt }}$ are obtained, the optimal $\mathrm{H}_{2}$ performance index $I_{\mathrm{C6} \text {,opt }}$ is

$$
I_{C 6, \mathrm{opt}}=\frac{\alpha^{2} \sqrt{8+6 \gamma^{2} \delta^{2}-24 \gamma \delta-2 \sqrt{9 \gamma^{4} \delta^{4}-72 \gamma^{3} \delta^{3}+184 \gamma^{2} \delta^{2}-160 \gamma \delta+16}}}{4 \gamma \delta w_{1}^{3}\left((9 / 8) \gamma^{2} \delta^{2}-(9 / 2) \gamma \delta+(5 / 2)-(3 / 8) \sqrt{9 \gamma^{4} \delta^{4}-72 \gamma^{3} \delta^{3}+184 \gamma^{2} \delta^{2}-160 \gamma \delta+16}\right)}
$$

2.2.7. Structure C7. The analytic expression of the $\mathrm{H}_{2}$ performance index of structure $\mathrm{C} 7$ is

$$
I_{C 7}=\frac{\alpha^{2}\left(4 \lambda^{2} \zeta^{2}+\gamma \delta+1\right)}{4 \gamma \zeta w_{1}^{3}(\gamma \delta+1)}
$$

For a given inertance-to-mass ratio $\delta$, the optimal stiffness ratio $\lambda_{\text {opt }}$ is

$$
\lambda_{\mathrm{opt}}=0
$$

For a given inertance-to-mass ratio $\delta$, the optimal damping ratio $\zeta_{\text {opt }}$ is $\infty$, and the optimal $\mathrm{H}_{2}$ performance index $I_{C 7 \text {,opt }}$ is 0 .

2.2.8. Structure C8. The analytic expression of the $\mathrm{H}_{2}$ performance index of structure $\mathrm{C} 8$ is

$$
I_{C 8}=\frac{\alpha^{2}}{4 \gamma \zeta w_{1}^{3}}
$$




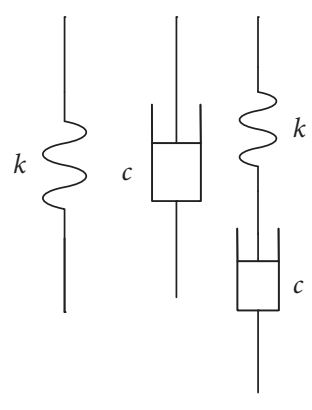

(a) (b) (c)

FIgURE 4: Simple structure after degradation: (a) TC1. (b) TC2. (c) TC3.

For a given inertance-to-mass ratio $\delta$, the optimal damping ratio $\zeta_{\text {opt }}$ is $\infty$, and the optimal $\mathrm{H}_{2}$ performance index $I_{C 8, \text { opt }}$ is 0 .

It should be noted that the $\mathrm{H}_{2}$ performance indexes of structures $\mathrm{C} 1, \mathrm{C} 2, \mathrm{C} 5, \mathrm{C} 7$, and $\mathrm{C} 8$ are optimized when the stiffness ratio $\lambda$ is zero or the damping ratio $\zeta$ is infinite. These structures will degenerate into simple structures as shown in Figure 4, in which $\mathrm{C} 1$ degenerates into $\mathrm{TC} 1$ or TC2, C2 degenerates into TC1, C5 and C7 degenerate into TC3, and C8 degenerates into TC2.

Although the $\mathrm{H}_{2}$ performance indexes of $\mathrm{C} 1, \mathrm{C} 2, \mathrm{C} 5, \mathrm{C} 7$, and $\mathrm{C} 8$ can be equal to zero in the optimal case, they need to have a damping ratio equal to infinity and a stiffness ratio equal to zero, which is impossible in practice. In addition, C1, C2, C5, $\mathrm{C} 7$, and $\mathrm{C} 8$ after degradation will have other disadvantages, which will be pointed out in the subsequent simulation experiments. $\mathrm{C} 3, \mathrm{C} 4$, and $\mathrm{C} 6$ can obtain the optimal $\mathrm{H}_{2}$ performance index under the condition of obtaining the optimal stiffness ratio and damping ratio. In practical applications, the optimal $\mathrm{H}_{2}$ performance can be obtained by selecting the corresponding optimal stiffness ratio and damping ratio.

\subsection{Analytic Solution of $\mathrm{H}_{2}$ Performance Optimization for} TMD. Similarly, the traditional TMD was installed in the multi-degree-of-freedom model and its damping performance was studied, and the schematic diagram of TMD installed in the multi-degree-of-freedom model is shown in Figure 5, ignoring the influence of damping of the main structure.

Its motion equation is

$$
\left\{\begin{array}{l}
M \ddot{X}+K X+F \Gamma_{n}=-M E \ddot{x}_{g} \\
F=m_{b}\left(\ddot{x}_{b}+\ddot{x}_{g}\right)=k\left(x_{n}-x_{b}\right) \\
+c\left(\dot{x}_{n}-\dot{x}_{b}\right)
\end{array}\right.
$$

where $M$ and $K$ are, respectively, the mass matrix and stiffness matrix of the main structure; $m_{b}, c$, and $k$ are the TMD mass, damping coefficient, and stiffness, respectively; $\ddot{X}$ and $X$ are the acceleration matrix and displacement

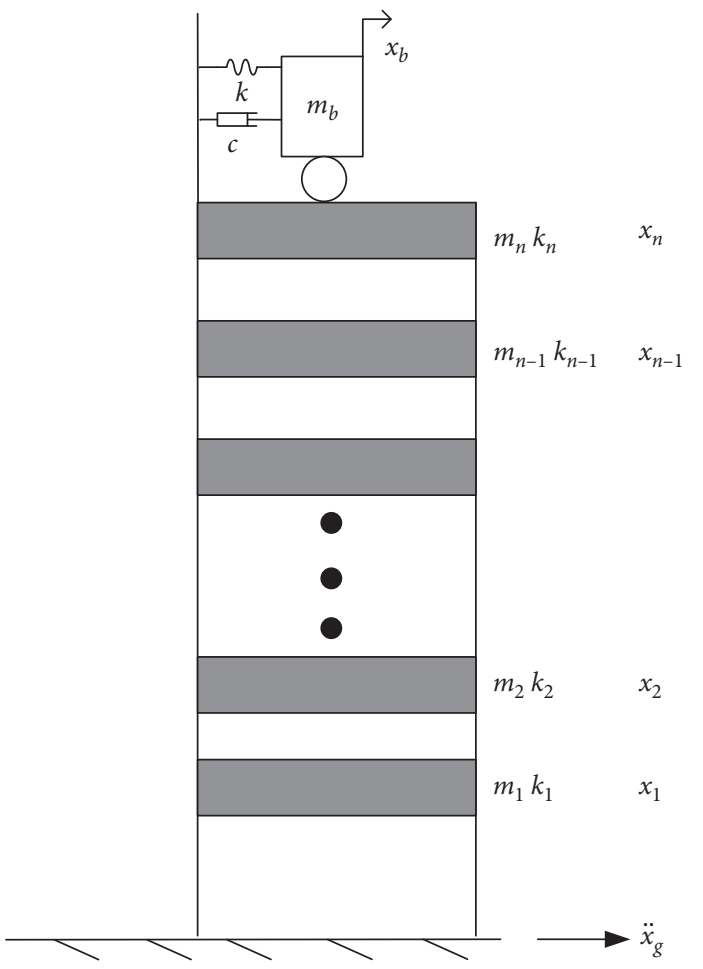

FIgURE 5: Schematic diagram of TMD installed in the multi-degree-of-freedom model.

matrix of the main structure, respectively, where $X=\left[x_{1}, x_{2}, \ldots, x_{n}\right]^{T} ; \ddot{x}_{b}, \dot{x}_{b}$, and $x_{b}$ are the acceleration, velocity, and displacement of the TMD, respectively. $\ddot{x}_{g}$ is earthquake acceleration; $\Gamma_{n}=[0,0, \ldots, 1]^{T}$ is the indicator vector for installation; $E=[1,1, \ldots, 1]^{T}$ is the unit volume; the mass matrix of the main structure $M=\operatorname{diag}\left(\left[m_{1}, m_{2}, \ldots, m_{n}\right]\right) ;$ and the stiffness matrix of the main structure $K=\left[\begin{array}{cccc}k_{1}+k_{2} & -k_{2} & \ldots & \\ -k_{2} & k_{2}+k_{3} & & \\ \vdots & & & -k_{n} \\ & & -k_{n} & k_{n}\end{array}\right]$; the above responses are the response to the ground. 
Let $X=\phi_{1} q$, where $\phi_{1}$ is the first mode and $q$ is the generalized displacement; by substituting it into equation (29) and carrying out the Laplace transform of equation (29), the transfer function of seismic acceleration to the displacement of the main structure can be obtained:

$$
H(s)=\frac{q}{\ddot{x}_{g}}=\frac{-\alpha\left(\delta_{\mathrm{TMD}} s^{2}+2 \zeta w_{1} s+w_{1}^{2} / \lambda\right)-\beta \delta_{\mathrm{TMD}}\left(2 \zeta w_{1} s+w_{1}^{2} / \lambda\right)}{\left(s^{2}+w_{1}^{2}\right)\left(\delta_{\mathrm{TMD}} s^{2}+2 \zeta w_{1} s+w_{1}^{2} / \lambda\right)+\gamma_{n} \delta_{\mathrm{TMD}} s^{2}\left(2 \zeta w_{1} s+w_{1}^{2} / \lambda\right)},
$$

where $w_{1}=\sqrt{K_{1} / M_{1}}$ is the first mode frequency, $M_{1}$ is the mass of the first mode, $K_{1}$ is the stiffness of the first mode, and $\delta_{\text {TMD }}=\left(m_{b} / M_{1}\right)$ is TMD mass ratio; damping ratio is $\zeta=\left(c / c_{r}\right)$, where $c_{r}=2 w_{1} M_{1}=2 \sqrt{M_{1} K_{1}}$ is the critical damping coefficient of the system without TMD; stiffness ratio $\quad$ is $\quad \lambda=\left(K_{1} / k\right) ; \quad \alpha=\left(\phi_{1}^{T} M E / M_{1}\right)$; $\beta=\phi_{1}^{T} \Gamma_{n} ; \gamma_{n}=\phi_{1}^{T} \Gamma_{n} \phi_{1(n)}$, where $\phi_{1(n)}$ is the first mode coordinates of the top layer.
TMD structure is optimized by using the above method of the $\mathrm{H}_{2}$ optimization of inerter-based isolator, and the analytic solution of $\mathrm{H}_{2}$ performance optimization of similar structures $\mathrm{C} 1-\mathrm{C} 8$, as well as the analytic expressions of optimal stiffness ratio $\lambda_{\text {opt }}$ and optimal damping ratio $\zeta_{\text {opt }}$, is obtained.

The analytic expression of the $\mathrm{H}_{2}$ performance index of TMD structure is

$$
I_{\mathrm{TMD}}=\frac{1}{4 \gamma_{n} \lambda^{2} \zeta w_{1}^{3} \delta_{\mathrm{TMD}}^{2}}\left(\begin{array}{c}
4 \beta^{2} \lambda^{2} \gamma_{n} \delta_{\mathrm{TMD}}^{3} \zeta^{2}+8 \alpha \beta \lambda^{2} \gamma_{n} \delta_{\mathrm{TMD}}^{2} \zeta^{2}+4 \alpha^{2} \lambda^{2} \gamma_{n} \delta_{\mathrm{TMD}} \zeta^{2} \\
+4 \beta^{2} \lambda^{2} \delta_{\mathrm{TMD}}^{2} \zeta^{2}+\beta^{2} \lambda \gamma_{n} \delta_{\mathrm{TMD}}^{4}+\beta^{2} \gamma_{n}^{2} \delta_{\mathrm{TMD}}^{4}+8 \alpha \beta \lambda^{2} \delta_{\mathrm{TMD}} \zeta^{2} \\
+2 \alpha \beta \gamma_{n}^{2} \delta_{\mathrm{TMD}}^{3}+\alpha^{2} \lambda^{2} \delta_{\mathrm{TMD}}^{2}+4 \alpha^{2} \lambda^{2} \zeta^{2}-\alpha^{2} \lambda \gamma_{n} \delta_{\mathrm{TMD}}^{2}+\alpha^{2} \gamma_{n}^{2} \delta_{\mathrm{TMD}}^{2} \\
+2 \beta^{2} \gamma_{n} \delta_{\mathrm{TMD}}^{3}-2 \alpha \beta \lambda \delta_{\mathrm{TMD}}^{2}+4 \alpha \beta \gamma_{n} \delta_{\mathrm{TMD}}^{2}-2 \alpha^{2} \lambda \delta_{\mathrm{TMD}} \\
+2 \alpha^{2} \gamma_{n} \delta_{\mathrm{TMD}}+\beta^{2} \delta_{\mathrm{TMD}}^{2}+2 \alpha \beta \delta_{\mathrm{TMD}}+\alpha^{2}
\end{array}\right)
$$

For a given TMD mass ratio $\delta_{\text {TMD }}$, the optimal stiffness ratio $\lambda_{\text {opt }}$ is

$$
\lambda_{\mathrm{opt}}=\frac{2\left(\beta \gamma_{n}^{2} \delta_{\mathrm{TMD}}^{3}+\alpha \gamma_{n}^{2} \delta_{\mathrm{TMD}}^{2}+2 \beta \gamma_{n} \delta_{\mathrm{TMD}}^{2}+2 \alpha \gamma_{n} \delta_{\mathrm{TMD}}+\beta \delta_{\mathrm{TMD}}+\alpha\right)}{\delta\left(-\beta \gamma_{n} \delta_{\mathrm{TMD}}^{2}+\alpha \gamma_{n} \delta_{\mathrm{TMD}}+2 \alpha\right)} .
$$

For a given TMD mass ratio $\delta_{\mathrm{TMD}}$, the optimal damping ratio $\zeta_{\text {opt }}$ is

$$
\zeta_{\mathrm{opt}}=\frac{\delta \sqrt{\left(-\beta \gamma_{n}^{2} \delta_{\mathrm{TMD}}^{3}+3 \alpha \gamma_{n}^{2} \delta_{\mathrm{TMD}}^{2}+4 \alpha \gamma_{n} \delta_{\mathrm{TMD}}\right) /\left(16 \beta \gamma_{n} \delta_{\mathrm{TMD}}^{2}+16 \alpha \gamma_{n} \delta_{\mathrm{TMD}}+16 \beta \delta_{\mathrm{TMD}}+16 \alpha\right)}}{1+\gamma_{n} \delta_{\mathrm{TMD}}} .
$$

The optimal $\mathrm{H}_{2}$ performance index $I_{\mathrm{TMD} \text {,opt }}$ is

$$
I_{\mathrm{TMD}, \text { opt }}=\frac{-\beta^{2} \gamma_{n} \delta_{\mathrm{TMD}}^{3}+2 \alpha \beta \gamma_{n} \delta_{\mathrm{TMD}}^{2}+3 \alpha^{2} \gamma_{n} \delta_{\mathrm{TMD}}+4 \alpha \beta \delta_{\mathrm{TMD}}+4 \alpha^{2}}{8\left(1+\gamma_{n} \delta_{\mathrm{TMD}}\right) w_{1}^{3} \sqrt{\left(-\beta \gamma_{n}^{2} \delta_{\mathrm{TMD}}^{3}+3 \alpha \gamma_{n}^{2} \delta_{\mathrm{TMD}}^{2}+4 \alpha \gamma_{n} \delta_{\mathrm{TMD}}\right) /\left(16 \beta \gamma_{n} \delta_{\mathrm{TMD}}^{2}+16 \alpha \gamma_{n} \delta_{\mathrm{TMD}}+16 \beta \delta_{\mathrm{TMD}}+16 \alpha\right)}} .
$$




\section{Numerical Examples}

In this paper, the three-story uniform structure model used by Lazar [39] is employed. The mass of each floor is $1000 \mathrm{~kg}$, and the stiffness of each layer is $1500 \mathrm{kN} \mathrm{m}^{-1}$. Ignoring the damping of the main structure, El Centro north-south seismic wave is adopted for simulation, and the damping performance of TMD and inerter-based isolator is analyzed and compared. TMD mass ratios are $0.01,0.03,0.05$, and 0.07 . First of all, only the first mode is considered in the simulation experiment.

Inertance-to-mass ratio is five times that of TMD mass ratio [39]. TMD mass ratio is generally selected as $(0,0.1]$. Within this range, when the performance of the inerterbased isolators is superior to TMD, there will be a minimum multiple relationship between inertance-to-mass ratio and TMD mass ratio. Taking the configuration $\mathrm{C} 4$ as an example, the minimum multiplicity of $\delta$ in equation (16) for $I_{\mathrm{C} 4}$ to be less than $I_{\mathrm{TMD}}$ in equation (31) is 5 . This means that the inertance-to-mass ratio of $\mathrm{C} 4$ should be 5 times larger than the TMD mass ratio. In practice, the higher amplifications than 5 can be easily realized due to the mass amplification effect of inerter.

El Centro seismic wave is the first fully recorded seismic wave in human history, with a magnitude of 6.7 and an epicenter distance of $9.3 \mathrm{~km}$. The waveform with a duration of $30 \mathrm{~s}$ in the north-south direction is selected with a time interval of $0.02 \mathrm{~s}$ and a peak acceleration of $3.417 \mathrm{~m} \mathrm{~s}^{-2}$, and the El Centro seismic wave is shown in Figure 6.

Then, taking $\mathrm{C} 1$ as an example, the parameter selection method of $\mathrm{C} 1, \mathrm{C} 2, \mathrm{C} 5, \mathrm{C} 7$, and $\mathrm{C} 8$ in simulation is illustrated. $\mathrm{C} 1$ obtains the optimal $\mathrm{H}_{2}$ performance when the damping ratio $\zeta=\left(c / c_{r}\right)$ is infinite, which means that the damping coefficient $c$ is infinite, when the stiffness ratio $\lambda$ is fixed, and the $\mathrm{H}_{2}$ performance index with respect to damping ratio is shown in Figure 7 . It can be seen that when the damping ratio is 100 , the performance index flattens and is approximately 0 , and then $\mathrm{C} 1$ degenerates to TC2.

In the same way, $\mathrm{C} 1$ obtains the optimal $\mathrm{H}_{2}$ performance when the stiffness ratio $\lambda=\left(K_{1} / k\right)$ is 0 , which means that the stiffness coefficient $k$ is infinite, when the damping ratio $\zeta$ is fixed, and the $\mathrm{H}_{2}$ performance index with respect to stiffness coefficient is shown in Figure 8. It can be seen that when the stiffness coefficient is $100000 \mathrm{kN} \mathrm{m}^{-1}$, the performance index flattens and is approximately 0 , and then $\mathrm{C} 1$ degenerates to TC1. Under the excitation of El Centro seismic waves, the generalized displacement when $\delta_{\mathrm{TMD}}=0.07$ is shown in Figure 9.

As can be seen from Table 1, in terms of generalized displacement, structures $\mathrm{C} 3, \mathrm{C} 4$, and $\mathrm{C} 6$ have better performance than TMD. With the increase of TMD mass ratio, C3, C4, and C6 can obtain a greater performance improvement than TMD. When TMD mass ratio is 0.07 , structures C3, C4, and C6 can provide 9.39\%, 8.02\%, and $16.62 \%$ performance improvement, respectively. Structures TC1, TC2, and TC3 are better than other structures.

In order to illustrate the performance of the inerterbased isolator, a total of 11 seismic waves [42] are employed for the simulation experiment, and the power spectral

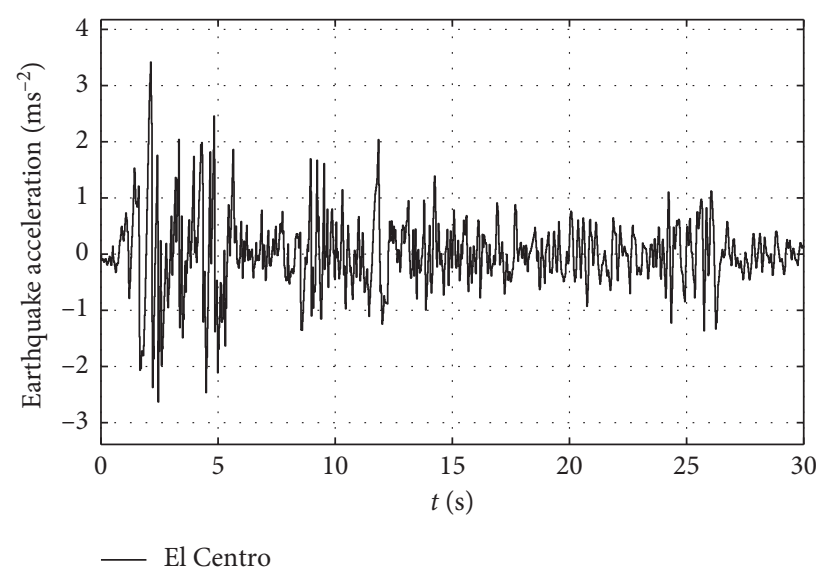

Figure 6: El Centro seismic wave.

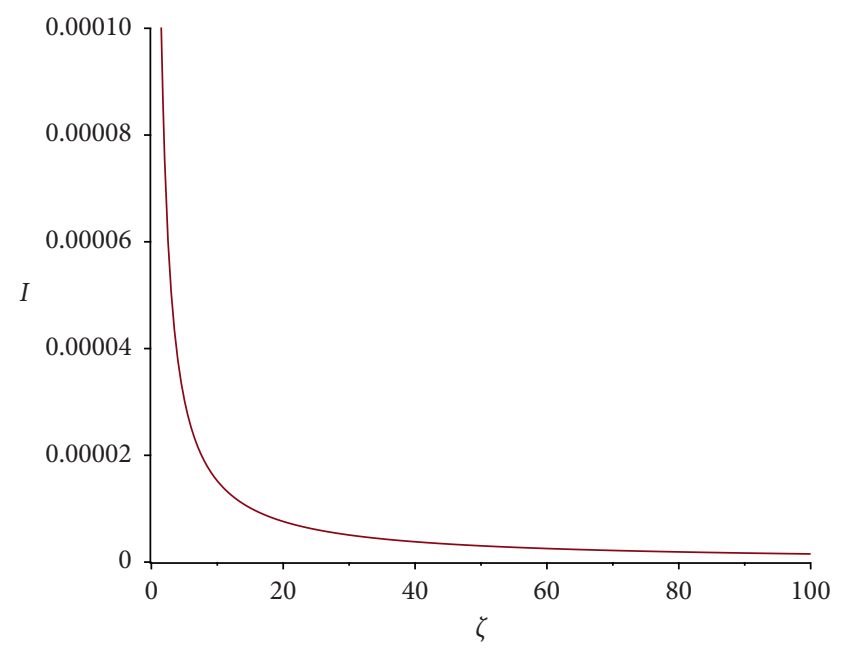

FIGURE 7: $\mathrm{H}_{2}$ performance index with respect to damping ratio for structure $\mathrm{C} 1$ under the excitation of El Centro seismic wave.

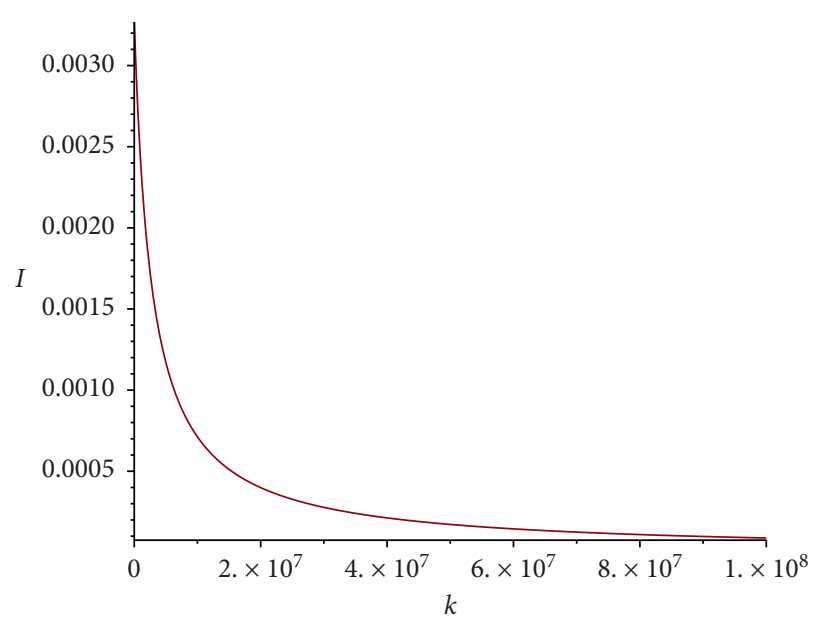

FIGURE 8: $\mathrm{H}_{2}$ performance index with respect to stiffness coefficient for structure $\mathrm{C} 1$ under the excitation of El Centro seismic wave. 


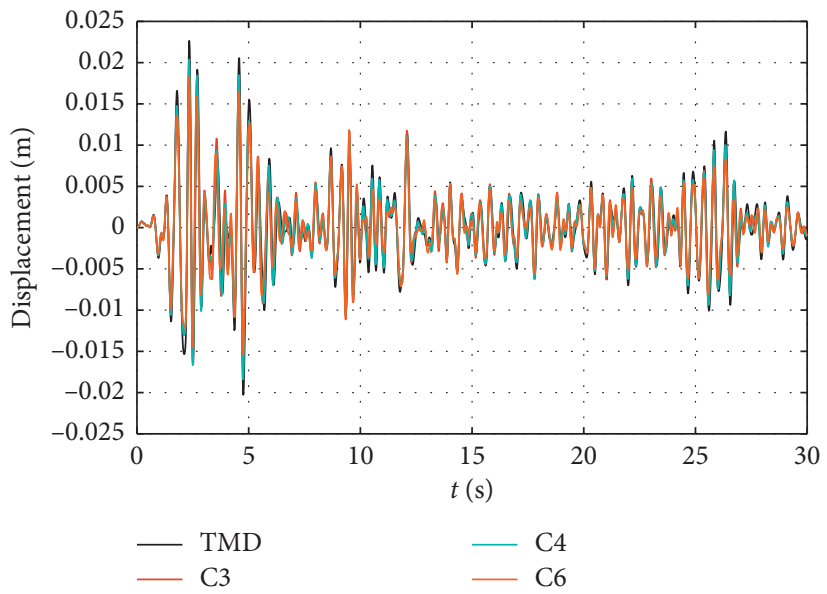

Figure 9: Generalized displacement when TMD mass ratio is 0.07 under the excitation of El Centro seismic wave.

TABLE 1: Root mean square of generalized displacement with different TMD mass ratios and different structures installed, unit $\left(\times 10^{-3} \mathrm{~m}\right)$.

\begin{tabular}{lcccccr}
\hline$\delta_{\text {TMD }}$ & TMD & C3 & C4 & C6 & TC1 & TC2 \\
\hline 0.01 & 6.079 & 6.025 & 6.019 & 5.999 & & \\
0.03 & 5.054 & 4.935 & 4.9 & 4.863 & 0.275 & 0.085 \\
0.05 & 4.868 & 4.569 & 4.563 & 4.365 & & 0.112 \\
0.07 & 4.813 & 4.631 & 4.426 & 4.013 & & \\
\hline
\end{tabular}

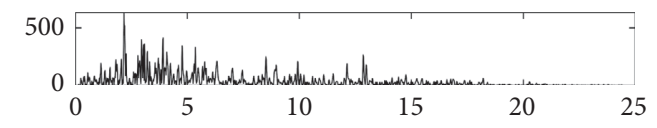

(a)

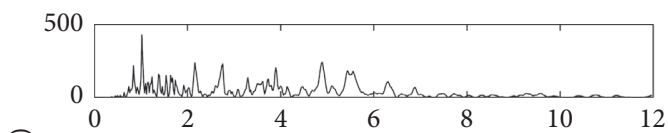

(c)

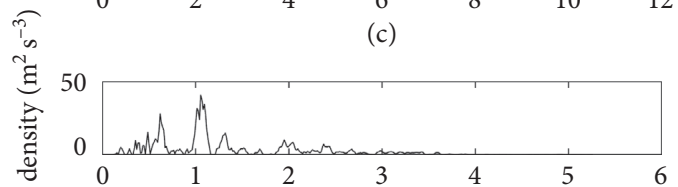

(e)

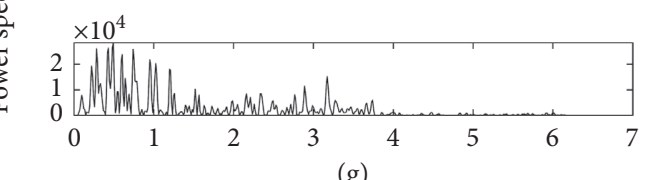

(g)

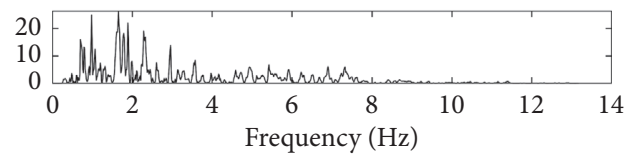

(i)

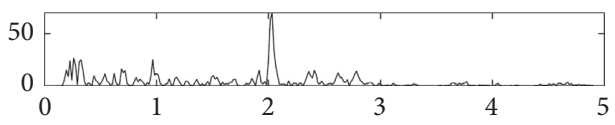

(b)

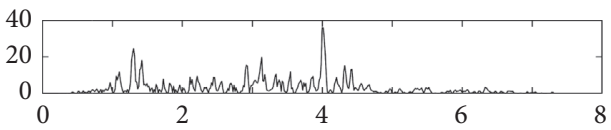

(d)

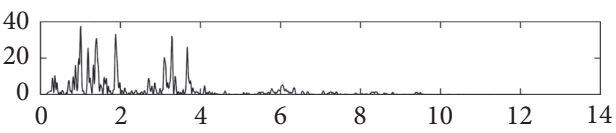

(f)

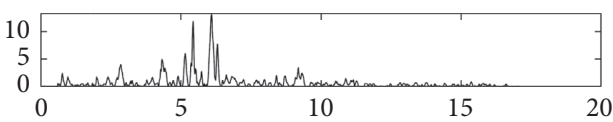

(h)

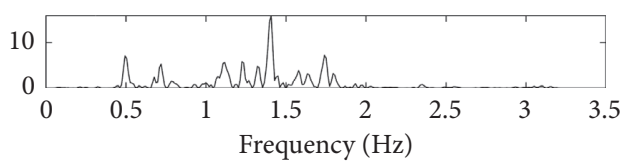

(j)

Figure 10: Power spectral density of various seismic wave accelerations. (a) Chichi. (b) Friuli. (c) Hollister. (d) Imperial Valley. (e) Kobe. (f) Kocaeli. (g) Landers. (h) Loma Prieta. (i) Northridge. (j) Trinidad.

density of various seismic wave accelerations is shown in Figure 10.

The comparative data of generalized displacement are summarized in Table 2, where $\delta_{T M D}=0.07$. It can be found that structures C3, C4, and C6 are much better than TMD in controlling the generalized displacement. Structures TC1, TC2, and TC 3 are better than other structures in controlling the generalized displacement.

After the simulation experiment of the simplified model is completed, the simulation experiment of the three-storey 
TABLE 2: Root mean square of generalized displacement with different earthquakes and different structures installed, unit $\left(\times 10^{-3} \mathrm{~m}\right)$.

\begin{tabular}{lcccccccc}
\hline Earthquake & PGA $(\mathrm{g})$ & TMD & C3 & C4 & C6 & TC1 & TC2 & TC3 \\
\hline Chichi & 0.3610 & 13.87 & 12.13 & 12.75 & 10.77 & 1.492 & 0.162 & 0.519 \\
El Centro & 0.3487 & 4.813 & 4.361 & 4.426 & 4.013 & 0.275 & 0.085 & 0.112 \\
Friuli & 0.3513 & 5.478 & 4.971 & 4.999 & 4.684 & 0.074 & 0.157 & 0.167 \\
Hollister & 0.1948 & 10.75 & 9.731 & 9.905 & 9.541 & 0.859 & 0.156 & 0.375 \\
Imperial Valley & 0.3152 & 5.7 & 5.408 & 5.381 & 4.874 & 0.103 & 0.063 & 0.1 \\
Kobe & 0.3447 & 4.921 & 4.663 & 4.608 & 4.29 & 0.136 & 0.154 & 0.169 \\
Kocaeli & 0.3490 & 4.026 & 3.865 & 3.771 & 3.483 & 0.069 & 0.091 & 0.109 \\
Landers & 0.7803 & 17 & 15.58 & 15.63 & 14.74 & 0.272 & 2.55 & 2.534 \\
Loma Prieta & 0.3674 & 2.106 & 1.909 & 1.955 & 1.816 & 0.26 & 0.035 & 0.113 \\
Northridge & 0.5683 & 8.147 & 7.727 & 7.801 & 6.853 & 0.295 & 0.127 & 0.179 \\
Trinidad & 0.1936 & 2.372 & 2.157 & 2.156 & 2.034 & 0.037 & 0.073 & 0.08 \\
\hline
\end{tabular}

TABLE 3: Root mean square of displacement of each floor with different structures installed, unit $\left(\times 10^{-3} \mathrm{~m}\right)$.

\begin{tabular}{lcccccccc}
\hline & Uncontrolled & TMD & C3 & C4 & C6 & TC1 & TC2 & TC3 \\
\hline First floor & 5.573 & 4.863 & 4.845 & 4.856 & 4.839 & 0.392 & 0.089 & 0.246 \\
Second floor & 9.722 & 8.696 & 8.663 & 8.686 & 8.658 & 26.48 & 11.55 & 15.2 \\
Third floor & 12.11 & 10.81 & 10.77 & 10.8 & 10.77 & 42.55 & 18.66 & 24.42 \\
\hline
\end{tabular}

structure mentioned above is carried out to verify the effectiveness of the optimal parameters. Taking structure C3 as an example, the state-space model is given.

Its motion equation is

$$
\left\{\begin{array}{l}
M \ddot{X}+K X+F \Gamma_{0}=-M E \ddot{x}_{g} \\
F=b x_{b}=k\left(x_{1}-x_{c}\right)=c\left(\dot{x}_{c}-\dot{x}_{b}\right)
\end{array}\right.
$$

Let

$$
Z=\left[\begin{array}{c}
X \\
\dot{X}
\end{array}\right]
$$

The state-space equation can be written as

$$
\begin{aligned}
\dot{Z} & =A Z+B U, \\
y & =C Z, \\
A & =\left[\begin{array}{cc}
0 & I \\
-M^{-1} K & 0
\end{array}\right], \\
B & =\left[\begin{array}{cc}
0 & 0 \\
-M^{-1} \Gamma_{0} & -E
\end{array}\right], \\
C & =\left[\begin{array}{cc}
I & 0
\end{array}\right], \\
U & =\left[\begin{array}{c}
F \\
\ddot{x}_{g}
\end{array}\right] .
\end{aligned}
$$

El Centro seismic wave is still used as seismic input, and the optimal parameters obtained from the simplified model are used for simulation; the displacement of each floor with different structures installed is summarized in Table 3, where $\delta_{\mathrm{TMD}}=0.07$.

As can be seen from Table 3, compared with uncontrolled structure, TMD, C3, C4, and C6 have a good control effect on the displacement of each floor, and C3, C4, and C6 have better performance than TMD. Although TC1, TC2, and TC3 can control the displacement of the first floor, they cannot control the displacement of the upper floor, which is the biggest disadvantage of TC1, TC2, and TC3.

Meanwhile, according to Table 3, the interstorey drifts of the two adjacent storeys can be calculated. Compared with an uncontrolled structure, TMD, C3, C4, and C6 reduce the interstorey drifts, and the interstorey drifts of $\mathrm{C} 3, \mathrm{C} 4$, and $\mathrm{C} 6$ are smaller than TMD, which can better avoid the destruction of buildings, while TC1, TC2, and TC3 increase the interstorey drifts.

It should be noted that although TC1, TC2, and TC3 have good $\mathrm{H}_{2}$ performance, in the case of multiple degrees of freedom, only the displacement of the first floor can be controlled, and the displacement of the upper floor will be large, which is not desirable. Therefore, the application of structures C3, C4, and C6 is more reasonable.

Note that the nonlinearities of the employed devices are not considered in this paper. However, as shown in the existing results such as [43-46], the nonlinear effects of inerter would make the constitutive behavior different from the linear one, especially at the low frequencies for civil engineering applications. This should be considered in the future.

\section{Conclusions}

In this paper, all the low-complexity networks containing one inerter, one spring, and one damper were employed for the base isolation problem in seismic applications. The analytical $\mathrm{H}_{2}$ optimization method was adopted based on a multi-degree-of-freedom model to derive the optimal solutions of the considered low-complexity networks. The performance comparison between these low-complexity networks as well as the TMD was conducted. Numerical simulations based on eleven seismic waves were performed to verify the results in this paper. It was found that some inerter-based isolators (such as C3, C4, and C6) are much 
better than TMD in controlling the displacement of the main structure, with the increase of TMD mass ratio, and some inerter-based isolators (such as C3, C4, and C6) can obtain a greater performance improvement than TMD.

\section{Data Availability}

The data used to support the findings of this study are available from the corresponding author upon request.

\section{Conflicts of Interest}

The authors declare that they have no conflicts of interest.

\section{Acknowledgments}

This research was partially supported by the Natural Science Foundation of China under grant nos. 61873129 and 61603122 and the Fundamental Research Funds for the Central Universities of China under grant no. 2019B14514.

\section{References}

[1] A. G. Piersol and T. L. Paez, Harris' Shock and Vibration Handbook, McGraw-Hill, New York, NY, USA, 2010.

[2] H. Frahm, "Device for damping vibrations of bodies," US Patent 989958, 1909.

[3] J. P. D. Hartog, Mechanical Vibrations, Dover Publications, New York, NY, USA, 1985.

[4] M. C. Smith, "Synthesis of mechanical networks: the inerter," IEEE Transactions on Automatic Control, vol. 47, no. 10, pp. 1648-1662, 2002.

[5] M. C. Smith, "The inerter: a retrospective," Annual Review of Control, Robotics, and Autonomous Systems, vol. 3, no. 1, pp. 361-391, 2020.

[6] M. Z. Q. Chen, C. Papageorgiou, F. Scheibe, F.-C. Wang, and M. C. Smith, "The missing mechanical circuit element," IEEE Circuits and Systems Magazine, vol. 9, no. 1, pp. 10-26, 2009.

[7] F.-C. Wang and W.-J. Su, "Impact of inerter nonlinearities on vehicle suspension control," Vehicle System Dynamics, vol. 46, no. 7, pp. 575-595, 2008.

[8] F.-C. Wang, M.-F. Hong, and T.-C. Lin, "Designing and testing a hydraulic inerter," Proceedings of the Institution of Mechanical Engineers, Part C: Journal of Mechanical Engineering Science, vol. 225, no. 1, pp. 66-72, 2011.

[9] B. J. Gartner and M. C. Smith, "Damper and inertial hydraulic device," US Patent 13/577 234, 2011.

[10] R. Tuluie, "Fluid inerter," US Patent 13/575 017, 2010.

[11] M. C. Smith and F.-C. Wang, "Performance benefits in passive vehicle suspensions employing inerters," Vehicle System Dynamics, vol. 42, no. 4, pp. 235-257, 2004.

[12] Y. Shen, L. Chen, X. Yang, D. Shi, and J. Yang, "Improved design of dynamic vibration absorber by using the inerter and its application in vehicle suspension," Journal of Sound and Vibration, vol. 361, pp. 148-158, 2016.

[13] Y. Hu, M. Z. Q. Chen, and Y. Sun, "Comfort-oriented vehicle suspension design with skyhook inerter configuration," Journal of Sound and Vibration, vol. 405, pp. 34-47, 2017.

[14] D. Ning, S. Sun, H. Du et al., "An electromagnetic variable inertance device for seat suspension vibration control," $\mathrm{Me}$ chanical Systems and Signal Processing, vol. 133, Article ID 106259, 2019.
[15] Y. Shen, L. Chen, Y. Liu, and X. Zhang, "Modeling and optimization of vehicle suspension employing a nonlinear fluid inerter," Shock and Vibration, vol. 2016, Article ID 2623017, 9 pages, 2016.

[16] Y. Liu, W. Zhao, X. Yang, L. Chen, and Y. Shen, "Predictive control of vehicle ISD suspension based on a hydraulic electric inerter," Shock and Vibration, vol. 2019, Article ID 9230736, 11 pages, 2019.

[17] F. Scheibe and M. C. Smith, "Analytical solutions for optimal ride comfort and tyre grip for passive vehicle suspensions," Vehicle System Dynamics, vol. 47, no. 10, pp. 1229-1252, 2009.

[18] Y. Hu, J. Wang, M. Z. Q. Chen, Z. Li, and Y. Sun, "Load mitigation for a barge-type floating offshore wind turbine via inerter-based passive structural control," Engineering Structures, vol. 177, pp. 198-209, 2018.

[19] S. Sarkar and B. Fitzgerald, "Vibration control of spar-type floating offshore wind turbine towers using a tuned massdamper-inerter," Structural Control and Health Monitoring, vol. 27, no. 1, Article ID e2471, 2020.

[20] R. Zhang, Z. Zhao, and K. Dai, "Seismic response mitigation of a wind turbine tower using a tuned parallel inerter mass system," Engineering Structures, vol. 180, pp. 29-39, 2019.

[21] C. Pan, R. Zhang, H. Luo, C. Li, and H. Shen, "Demand-based optimal design of oscillator with parallel-layout viscous inerter damper," Structural Control and Health Monitoring, vol. 25, no. 1, Article ID e2051, 2018.

[22] M. Wang and F. Sun, "Displacement reduction effect and simplified evaluation method for SDOF systems using a clutching inerter damper," Earthquake Engineering \& Structural Dynamics, vol. 47, no. 7, pp. 1651-1672, 2018.

[23] H. Sun, L. Zuo, X. Wang, J. Peng, and W. Wang, "Exact $\mathrm{H}_{2}$ optimal solutions to inerter-based isolation systems for building structures," Structural Control and Health Monitoring, vol. 26, no. 6, Article ID e2357, 2019.

[24] D. D. Domenico, H. Qiao, Q. Wang, Z. Zhu, and G. Marano, "Optimal design and seismic performance of multi-tuned mass damper inerter (MTMDI) applied to adjacent high-rise buildings," The Structural Design of Tall and Special Buildings, vol. 29, no. 14, Article ID e1781, 2020.

[25] A. Radu, I. F. Lazar, and S. A. Neild, "Performance-based seismic design of tuned inerter dampers," Structural Control and Health Monitoring, vol. 26, no. 5, Article ID e2346, 2019.

[26] H. Garrido, O. Curadelli, and D. Ambrosini, "Resettableinertance inerter: a semiactive control device for energy absorption," Structural Control and Health Monitoring, vol. 26, no. 11, Article ID e2415, 2019.

[27] L. Sun, D. Hong, and L. Chen, "Cables interconnected with tuned inerter damper for vibration mitigation," Engineering Structures, vol. 151, pp. 57-67, 2017.

[28] Y. Luo, H. Sun, X. Wang, L. Zuo, and N. Chen, "Wind induced vibration control and energy harvesting of electromagnetic resonant shunt tuned mass-damper-inerter for building structures," Shock and Vibration, vol. 2017, Article ID 4180134, 13 pages, 2017.

[29] Q. Xu, Y. Luo, H. Yao, L. Zhao, and B. Wen, "Eliminating the fluid-induced vibration and improving the stability of the rotor/seal system using the inerter-based dynamic vibration absorber," Shock and Vibration, vol. 2019, Article ID 1746563, 9 pages, 2019.

[30] S. Zhang, R. Zhang, and Z. Zhao, "Demand-based optimal design of storage tank with inerter system," Shock and Vibration, vol. 2017, Article ID 2956153, 14 pages, 2017.

[31] K. Bubbar and B. Buckham, "On establishing an analytical power capture limit for self-reacting point absorber wave 
energy converters based on dynamic response," Applied Energy, vol. 228, pp. 324-338, 2018.

[32] R. Haraguchi and T. Asai, "Enhanced power absorption of a point absorber wave energy converter using a tuned inertial mass," Energy, vol. 202, Article ID 117740, 2020.

[33] F.-C. Wang, M.-F. Hong, and C.-W. Chen, "Building suspensions with inerters," Proceedings of the Institution of Mechanical Engineers, Part C: Journal of Mechanical Engineering Science, vol. 224, no. 8, pp. 1605-1616, 2010.

[34] Y. Hu, M. Z. Q. Chen, Z. Shu, and L. Huang, "Analysis and optimisation for inerter-based isolators via fixed-point theory and algebraic solution," Journal of Sound and Vibration, vol. 346, pp. 17-36, 2015.

[35] Y. Hu, Analysis and design for inerter-based low-complexity mechanical vibration control systems, Ph.D. thesis, Nanjing University of Science and Technology, Nanjing, China, 2016.

[36] Y. Hu and M. Z. Q. Chen, "Performance evaluation for inerter-based dynamic vibration absorbers," International Journal of Mechanical Sciences, vol. 99, pp. 297-307, 2015.

[37] L. Marian and A. Giaralis, "Optimal design of a novel tuned mass-damper-inerter (TMDI) passive vibration control configuration for stochastically support-excited structural systems," Probabilistic Engineering Mechanics, vol. 38, pp. 156-164, 2014.

[38] K. Ikago, K. Saito, and N. Inoue, "Seismic control of singledegree-of-freedom structure using tuned viscous mass damper," Earthquake Engineering \& Structural Dynamics, vol. 41, no. 3, pp. 453-474, 2012.

[39] I. F. Lazar, S. A. Neild, and D. J. Wagg, "Using an inerterbased device for structural vibration suppression," Earthquake Engineering \& Structural Dynamics, vol. 43, no. 8, pp. 1129-1147, 2014.

[40] L. Liu, P. Tan, W. Yan, X. Li, and F. Zhou, "Design of a novel inerter damper and its aseismic effect under earthquake," Journal of Vibration and Shock, vol. 38, no. 4, pp. 751-757, 2018.

[41] K. Zhou, J. C. Doyle, and K. Glover, Robust and Optimal Control, Prentice-Hall, Upper Saddle River, NJ, USA, 1996.

[42] Pacific Earthquake Engineering Research Center, PEER Ground Motion Database, Pacific Earthquake Engineering Research Center, Berkeley, CA, USA, 2014, https://ngawest2. berkeley.edu.

[43] D. D. Domenico, G. Ricciardi, and R. Zhang, "Optimal design and seismic performance of tuned fluid inerter applied to structures with friction pendulum isolators," Soil Dynamics and Earthquake Engineering, vol. 132, Article ID 106099, 2020.

[44] D. D. Domenico, P. Deastra, G. Ricciardi, N. D. Sims, and D. J. Wagg, "Novel fluid inerter based tuned mass dampers for optimised structural control of base-isolated buildings," Journal of the Franklin Institute, vol. 356, no. 14, pp. 76267649, 2019.

[45] A. G. Buelga, I. F. Lazar, J. Z. Jiang, S. A. Neild, and D. J. Inman, "Assessing the effect of nonlinearities on the performance of a tuned inerter damper," Structural Control and Health Monitoring, vol. 24, no. 3, Article ID e1879, 2017.

[46] R. M. Hessabi and O. Mercan, "Investigations of the application of gyro-mass dampers with various types of supplemental dampers for vibration control of building structures," Engineering Structures, vol. 126, pp. 174-186, 2016. 